\title{
A study of Autonomic Dysfunction in bronchial asthma patients in a tertiary care centre of central India
}

\author{
Mourya $S^{1}$, Kumar $R^{2}$, Bajai $A^{3}$, Jhaver $D^{4}$, Mourya $S^{5}$ \\ ${ }^{1}$ Dr Sudhir Mourya, Associate Professor of Medicine, Index Medical College, Indore, MP, India, ${ }^{2}$ Dr Ratan Kumar, Assistant \\ Professor of Pulmonary Medicine, L N Medical College, Bhopal, MP, ${ }^{3}$ Dr A Bajpai, Professor of Medicine, MGM Medical \\ College, Indore, MP, ${ }^{4}$ Dr D Jhaver, Assistant Professor of Medicine, MGM Medical College, Indore, MP, ${ }^{5}$ Dr Shivani \\ Mourya, Consultant Ophthalmologist, Indore, MP, India.
}

Address for correspondence: Dr. Sudhir Mourya, Email: drmouryasudhir@gmail.com

\begin{abstract}
Introduction: bronchial asthma is a chronic inflammatory disorders of airways characterised by exaggerated bronchoconstriction due to certain indirect (e g dust, pollen, allergens, cold air) or direct (inhaled methacholine) stimuli. Autonomic system plays an important role in regulation of airways and their secretion. This study was planned to demonstrate existence of autonomic dysfunction in pathophysiology of bronchial asthma. Material \& Methods: Present study is undertaken in 45 subjects who were divided in to 2 groups cases and controls depending up on age and sex and similar characteristics. 7 different non-invasive tests are applied in to all subjects to evaluate their autonomic function status. Results: It was found that out of 45 patients 33 patients had abnormal autonomic function tests. Comparing the duration of bronchial asthma, 12 patients had duration $<5$ years out of this 3 patients with duration of asthma $<5$ years had abnormal test the rest 9 had normal tests whereas 33 patients had bronchial asthma for $>5$ years out of these 30 had abnormal tests and only 3 patients had normal test. Comparing the severity of bronchial asthma and autonomic dysfunction, Out of 45 patients 24 were classified as having severe bronchial asthma. 21 of the study patients had only parasympathetic dysfunction i.e. $46.66 \%$. 12 had both sympathetic and parasympathetic dysfunction i.e.40\% and only 6 had isolated sympathetic dysfunction i.e. $13.33 \%$. Conclusions: There is higher incidence of autonomic dysfunction in bronchial asthma patients. Parasympathetic hyper responsiveness appears to be the main pathological factor in the genesis of bronchial asthma
\end{abstract}

Key words: Asthma, Autonomic dysfunction, bronchoconstriction

\section{Introduction}

Bronchial asthma is a major chronic airway disorder which is a serious public health problem in countries throughout the world. In this inflammatory disease many cells play a role, particularly mast cells, eosinophils and $\mathrm{T}$ lymphocytes. In susceptible individuals this inflammation causes recurrent episode of wheezing, breathlessness, chest tightness and cough, particularly at night and/or in early morning.

Asthma is now one of the world's most common chronic inflammatory conditions, according to the global burden of asthma report. WHO estimates that 235 million people currently suffer from asthma [1].

Airway system is innervated by four nervous systems: cholinergic, adrenergic, inhibitory nonadrenergic noncholinergic (i-NANC) and excitatory NANC (e-NANC). Alteration in function of any systems may be involved in inflammation or hyper -responsiveness observed in

Manuscript received: $15^{\text {th }}$ Dec 2013

Reviewed: $05^{\text {th }}$ Jan 2014

Author Corrected: $13^{\text {th }}$ Jan 2014

Accepted for Publication: $01^{\text {st }}$ Feb 2014 asthmatic patients. Thus, several types of autonomic dysfunction have been proposed in asthma; enhanced cholinergic, $\alpha$ - adrenergic, excitatory non-adrenergic noncholinergic (e-NANC) bronchoconstrictor mechanisms and reduced $\beta$-adrenergic and inhibitory NANC (iNANC) bronchodilator mechanisms [2].

Different non-invasive, safe and easily predictable cardiovascular autonomic reflex function tests are used to evaluate autonomic function in asthma. Enhanced parasympathetic activity is considered as an important factor in pathogenesis of bronchial hyperactivity [3].

This hyperactivity is generally co-existent with airway inflammation and is associated with altered sensory neuronal activity [4].

The objective of present study is to evaluate the autonomic dysfunction in bronchial asthma and to determine its co-relation with duration and severity of asthma. 


\section{Aims and Objectives}

The present study is planned:

1. To evaluate autonomic nervous dysfunction in patient with bronchial asthma by 7 non invasive test.

2. To determine the relationship of duration of asthma with expected autonomic nervous system dysfunction

3. Comparison of severity of bronchial asthma with incidence of autonomic nervous dysfunction.

\section{Material and Methods}

Present study was conducted in tertiary care teaching hospital after taking permission from Institutional ethical committee.

\section{Inclusion criteria}

- Bronchial Asthma Patients

\section{Exclusion criteria}

- Hypertension

- Diabetes mellitus

- Ischaemic heart disease

- Drugs causing autonomic dysfunction

- Alcoholic patients

The study protocol

Informed consent was obtained both from the patients and the control group. The investigations were performed in calm setting, after a rest of 10 minutes with considerable gap in between the test so as to minimise discomfort to the subjects as well as to enhance their enthusiastic participation and better results of the test. Normal sinus rhythm was confirmed in all subjects and controls. All the tests were explained to the subjects and controls. Detailed history and examination was done of all the subjects and controls and of the subjects regarding primary illness, sign's and symptom's of autonomic dysfunctions.

The subjects were divided in to three groups depending upon the severity of the diseases.

All the subjects and controls were monitored for the heart rate by an electrocardiogram and the blood pressure was monitored in the right upper extremity by a sphygmomanometer after adequate physical rest and mental reassurance. Blood pressure and heart rates were recorded at the beginning and after continuous rest.

The autonomic function tests were commenced when two consecutive heart rates and blood pressure readings taken five minutes apart were same, which meant that in all probability they had reached their basal values. Each subject thus rested for about ten minutes before the tests were started.

First deep breathing exercise was done for 1 minute followed by valsalva maneuver, cold pressor test and sustained hand grip test. Following this the subjects and controls were made to stand from supine position for the orthostatic test. Lastly, they were made to lie down and 1.8 to $3.0 \mathrm{mg}(0.4 \mathrm{mg} / \mathrm{kg}$ body weight $)$ of atropine sulphate was injected intravenously for the Atropine test. Care was taken to see that heart rate and blood pressure returned to the basal levels before commencing the next test.

The subjects who were not co-operative or unable to carry out the test properly were excluded from the study, since the results of deep breathing, valsalva maneuver and hand grip test were very much dependent on co-operation and effort of the subject.

\section{Results}

Table No-1: General Subjects Characteristics

\begin{tabular}{|l|l|l|l|l|}
\hline Gender & Patients & Percentage & Controls & Percentage \\
\hline Males & 18 & $40 \%$ & 6 & $30 \%$ \\
\hline Females & 27 & $60 \%$ & 14 & $70 \%$ \\
\hline
\end{tabular}

Patients included in study were 45 out of which 18 are males and 27 females \& among 20 controls 6 are males and 14 females.

Table No-2: Number of Subjects with Autonomic dysfunction

\begin{tabular}{|l|l|l|l|l|}
\hline & Control & Percentage & Patient & Percentage \\
\hline Normal & 20 & $100 \%$ & 12 & $26.66 \%$ \\
\hline Abnormal & 0 & $0 \%$ & 33 & $73.33 \%$ \\
\hline
\end{tabular}

In the study out of 45 patients of bronchial asthma $33(73 \%)$ had abnormal tests \& all the control patients had normal autonomic functions. 
Table No-3: Comparison of duration of Asthma with Autonomic dysfunction

\begin{tabular}{|l|l|l|l|l|}
\hline Autonomic & Duration < 5 yrs & Percentage & Duration > 5 yrs & percentage \\
\hline Normal & 9 & $75 \%$ & 3 & $9.09 \%$ \\
\hline Abnormal & 3 & $25 \%$ & 30 & $90.9 \%$ \\
\hline
\end{tabular}

When duration of disease is less than 5 years $25 \%$ have abnormal test, while when duration is more than 5 years almost $91 \%$ have abnormal test.

Table No-4: Comparison between Severity of Asthma and Number of patients with Autonomic dysfunction

\begin{tabular}{|l|l|l|l|l|}
\hline Autonomic & Mild to moderate & percentage & Severe & percentage \\
\hline Normal & 10 & $47.61 \%$ & 2 & $8.33 \%$ \\
\hline Abnormal & 11 & $52.38 \%$ & 22 & $91.66 \%$ \\
\hline
\end{tabular}

Above table shows that 24 patients had severe asthma out of which 22 (92\%) have autonomic dysfunctions. Out of 21 mild to moderate degree asthma patients $11(52 \%)$ had abnormal autonomic function.

Table No-5: Representation of Autonomic dysfunction in Bronchial asthma patients

\begin{tabular}{|l|l|l|}
\hline Parasympathetic dysfunction & Sympathetic dysfunction & Both \\
\hline $21(46.67 \%)$ & $6(13.33 \%)$ & $12(40 \%)$ \\
\hline
\end{tabular}

In this study if we compare sympathetic and parasympathetic dysfunction, parasympathetic dysfunction was seen in most of patients $(46.67 \%)$.

Table No-6: Categories into Which Autonomic dysfunction divided

\begin{tabular}{|l|l|l|}
\hline & Number & Percentage \\
\hline Normal & 12 & $26.66 \%$ \\
\hline Early & 3 & $6.66 \%$ \\
\hline Definite & 3 & $6.66 \%$ \\
\hline Severe & 12 & $26.66 \%$ \\
\hline Atypical & 15 & $33.33 \%$ \\
\hline
\end{tabular}

Normal: All test were normal or borderline

Early: 2 heart rate test borderline or 1 heart rate test abnormal, BP test normal

Definite: 2 heart rate test abnormal and BP test normal

Severe: 2 heart rate test abnormal and 2 BP test borderline

Atypical: Any other combination of test

\section{Discussion}

The study population considered of 18 males and 27 females and 6 males and 14 females among control population. Duration was taken from the time of patient being diagnosed or having bronchial asthma till the date of performing the test. The duration varied from 8 month to 40 years. 7 non- invasive test for testing autonomic nervous system were performed. 1) Deep breathing test, 2) Atropine test, 3) 30:15 ratio, 4) Valsalva maneuver 5) Orthostatic test, 6) Sustained hand grip test, 7) Cold pressor test. It was found that out of 45 patients 33 patients had abnormal autonomic function tests and 12 had normal test. Most of our patients had more than one abnormal test. Control had all normal tests $(\mathrm{P}<0.001)$. This shows that bronchial asthma do have significant autonomic dysfunction.
Sharma B et al (2003) demonstrate autonomic dysfunction in $22(73.33 \%)$ asthmatic patients out of 30 asthmatic patients [5]. Shah P. K.D. et al (1990) also found significant prevalence of autonomic dysfunction in asthmatic patient [6]. Patients were further classified as those having early definite, severe or atypical involvement.

Any patient who did not fit into the category of early, definite or severe was considered as atypical. Most of patients fall into the atypical category i.e.33\%.

A comparison was made between the relation between duration of asthma and number of patients with abnormal autonomic function. Arbitrarily duration was taken as $<5$ years and $>5$ years. 
12 patients had duration $<5$ years out of this 3 patients with duration of asthma $<5$ years had abnormal test the rest 9 had normal tests whereas 33 patients had bronchial asthma for $>5$ years out of these 30 had abnormal tests and only 3 patients had normal test. $\mathrm{P}$ value $<0.001$ indicating that with chronicity the autonomic dysfunction increases.

Comparing the severity of bronchial asthma and autonomic dysfunction, severity was defined on the basis of symptoms, number of hospitalization, number of exacerbation daily use of B2 agonist, PEF variability and bet PEF (table 1). Out of 45 patients 24 were classified as having severe bronchial asthma and 21 as not severe. Out of these 24 patients, only 2 had normal autonomic function test rest 22 had autonomic dysfunction; out of 21 patients classified as having mild to moderate asthma only 11 had evidence of autonomic dysfunction $(\mathrm{P}<0.001)$.

Thus it indicated that with severity the autonomic dysfunction increases. This is in confirmation with the findings of Sharma B et al (2003) who demonstrate that as the severity of asthma increases, the incidence of autonomic dysfunction also increases.

In his study severe asthma was present in 16 patients out of which 15 patients had autonomic dysfunction [5]. Shah P.K.D. et al (1990) observed significant autonomic dysfunction with the increasing severity of disease $(\mathrm{p}<0.001)[6]$.

Out of the 18 male patients, 14 had abnormal tests and 4 patients did not have evidence of autonomic dysfunction whereas 19 out of 27 females had autonomic dysfunction and 8 had normal tests. $\mathrm{P}<0.10$ which implies that autonomic dysfunction is observed irrespective of either sex.

Kallenbach JM et al(1985) carried out similar studies which demonstrate reflex rate in asthma. They postulated that an abnormality in the autonomic control of airway calibre might be reflected by a parallel change in the reflex control of heart rate. They examined the heart rate variation induced by deep breathing (respiratory sinus arrhythmia), Valsalva maneuver, and standing up from the recumbent position in asthmatic subject and non asthmatic control subjects. Asthmatic patients had evidence of enhanced parasympathetic neural drive to the sinoatrial node, as manifested by a significantly greater magnitude of respiratory sinus arrhythmia, then the control ( $\mathrm{p}$ less then 0.0005). They were unable to induce a similar change in normal subjects by resistance breathing. A statistical analysis suggested the presence of a relationship between the magnitude of respiratory sinus arrhythmia and the degree of bronchial hyper reactivity in a group of asthmatic patients. Their results support the hypothesis that enhanced parasympathetic activity is an important factor in the pathogenesis of bronchial asthma [3].
Mitkari S.P. et al (2011) done a study with aimed to explore and validate status of sympathetic and parasympathetic division of autonomic nervous system in asthmatic patients by using battery of simplest and noninvasive tests.

The study involved 100 subjects (age group 30-60 years) out of which 50 were asthmatics and 50 were healthy volunteers. In all the study subject six different noninvasive, simple, standardized autonomic function tests were done.

The values in the tests assessing parasympathetic division were significantly lower in asthmatic patients as compared to control subjects $(\mathrm{P}<0.001)$. The results suggest that there is good evidence about autonomic dysfunction in asthmatic patients.

Though, both sympathetic and parasympathetic nervous system was found to be affected, more affection was of parasympathetic division [8]. In our study Parasympathetic test were abnormal in 21 (46 \%) while sympathetic system is involved in 12 patients.

Borse $\mathrm{S}$ et al (2013) demonstrate a study that 40 patients with bronchial asthma and healthy subjects matched for age and sex were subjected to standardized tests to evaluate autonomic nervous system.

Tests requiring stimulation of the parasympathetic system e.g Deep breathing test, valsalva maneuver, showed heightened response. In deep breathing test $\mathrm{P}$ value was significant ( $\mathrm{p}$ value $<.005)$. In Valsalva maneuver $\mathrm{P}$ value was significant $(\mathrm{P}<0.001)$. Postural fall of blood pressure and sustained hand grip chiefly concerned with evaluation of sympathetic system did not show significant differences so these results suggest that hyper responsiveness of the parasympathetic system might be an important factor in pathogenesis of bronchial asthma [9]. Results are similar to our study.

\section{Conclusion}

1. Bronchial asthma patients display definitive dysfunction of autonomic nervous system as compared with age and sex matched controls.

2. With chronicity more incidence of autonomic dysfunction is observed.

3. As the severity of asthma increases as judged by symptoms, PEF variability use of B2 agonist and dose of inhaled steroids it is observed that the incidence of autonomic dysfunction also increases.

4. Parasympathetic hyperresponsiveness appears to be the main pathological factor in the genesis of bronchial asthma and hence role of anticholinergics in treatment of asthma is very vital. 
Funding: Nil

Conflict of interest: Nil

Permission from IRB: Yes

\section{References}

1. WHO: Asthma, factsheet N"307 updated November 2013. Cited from http://www.who.int/mediacentre /factsheets/fs307/en/ on $17^{\text {th }}$ April 2014.

2. Barnes PJ. Is Asthma a nervous disease ? Chest 107; 3; 1995; supplement: 119S-124S.

3. Kallenbach JM, Webster T, Dowdeswell R, Reinach SG, Millar RN, Zwi S. Reflex heart rate control in asthma : Evidence of parasympathetic overactivity. Chest. 1985 May;87(5):644-8

4. Lewis MJ, Short AL, Lewis KE. Autonomic nervous system control of the cardiovascular and respiratory system in asthma. Respir Med. 2006 Oct;100(10):1688705 .
5. Sharma B, Daga M K., Sachdev G K., Kaushik M. A Study of Autonomic Dysfunction in Adult Asthma Patients at a Tertiary Care Center. Chest; October 29, 2003.

6. Shah PK, Lakhotia M, Mehta S, Jain SK, Gupta GL. Clinical dysautonomia in patients with bronchial asthma. Study with seven autonomic function tests. Chest 1990 Dec; 98(6):1408-13.

7. Mitkari S.P, Pazare P.A, Pawar S.M.autonomic dysfunction in patients with bronchial asthma : Int J Biol Med Res. 2011; 2(4): 852 - 855 .

8. Borse S, Pathak KP, Shah J : autonomic dysfunction in bronchial asthma : Indian Journal Of Applied Research;2013;3(9) :464-465

\section{How to cite this article?}

Mourya S, Kumar R, Bajai A, Jhaver D, Mourya S. A study of Autonomic Dysfunction in bronchial asthma patients in a tertiary care centre of central India. Int J Med Res Rev 2014;2(2):135-139. doi:10.17511/ijmrr.2014.i02.12 